\title{
Factors Influencing the Investor's Decision Making: The Moderating Role of Locus of Control
}

\author{
Hafiz Waqas KAMRAN ${ }^{1}$, Abthal QAISAR ${ }^{2}$, Nayyer SULTANA ${ }^{3}$, \\ Muhammad Atif NAWAZ ${ }^{4}$, Hafiz Tanveer AHMAD 5
}

Received: September 01, 2020 Revised: October 26, 2020 Accepted: November 05, 2020

\begin{abstract}
Investors from the whole world are looking for those stock markets that are less affected by interest rates. Pakistan is a good place to invest and the investors from the whole world are considering Pakistan for future ventures. The current study, therefore, aims to analyze the factors affecting investors' decision making in Pakistan with the interaction effect of locus of control. The primary data are gathered from 300 respondents. Structural equation modelling (SEM-PLS) is used to analyze the interactions among variables. The study finds positive impact of availability and representative biases on investment decision making. The study could not find any moderating role of locus of control. The results imply that decisions made by Pakistani investors are driven by the most easily or currently available information and they trust on the information obtained from family and friends without any authentication and verification. One possible description of insignificant moderation effect of locus of control can be the sample traits used in the study, e.g., personal characteristics, that change from culture to culture. Another description of these findings may be the association between heuristic biases, including availability, representative and psychological biases and decision-making regarding investment is not personality specific.
\end{abstract}

Keywords: Representative Bias, Availability Bias, Psychology Bias, Investment Decision Making, Locus of Control

JEL Classification Code: E44, F31, F37, G15

\section{Introduction}

A place where buying and selling of shares occurs is referred to as a stock market. For any economy, the stock market acts as a financing source for the investment of a business concern. The stock markets are the yardsticks for

${ }^{1}$ First Author and Corresponding Author. Assistant Professor, Faculty of Business Administration, Iqra University, Karachi, Pakistan [Postal Address: Iqra University, Defense View, Shaheed-e-Millat Road, Karachi, Pakistan] Email: hafiz.waqas@iqra.edu.pk

'Lyallpur Business School, Government College University, Faisalabad, Pakistan. Email: ibtahalqaisar2831@gmail.com

${ }^{3}$ Lecturer, Department of Public Administration, Government College Women University, Faisalabad, Pakistan. Email: nyrlashari@gmail.com ${ }^{4}$ Lecturer, Department of Economics, The Islamia University of Bahawalpur, Pakistan. Email: atif.nawaz@iub.edu.pk

${ }^{5}$ Lyallpur Business School, Government College University,

Faisalabad, Pakistan. Email: thetanveer437@gmail.com

(c) Copyright: The Author(s)

This is an Open Access article distributed under the terms of the Creative Commons Attribution Non-Commercial License (https://creativecommons.org/licenses/by-nc/4.0/) which permits unrestricted non-commercial use, distribution, and reproduction in any medium, provided the original work is properly cited. the strength of an economy and for the development of a country. Although, the stock price movements or the market trends represent a country's economic health. An increase in the prices of shares represent a positive sign for an economy. Pakistan as an emerging country, is considered to be the best stock performing market in Asia for the period of 2016, even it stands at number fifth globally. Investors from the whole world are looking for those stock markets that are less affected by the interest rates. Pakistan is a good place to invest and the investors from the whole world are considering Pakistan for future ventures. Therefore, it is of vital importance to study the behavior of investors working in the stock market of Pakistan, and the factors affecting their investment behavior (IB).

IB is an advanced part of behavioral finance which elaborates on how the decision-making process such as collecting the information, and understanding the situation expected, explored and evaluated by an investor. This process is known as IB (Arrfelt, Wiseman \& Hult, 2013). Most of the research in finance has been conducted on the rational IB which deliberates that the rationality of an investor leads to an efficient market outcome. The supposition behind 
the rationality of an investor is the utility maximization nature of an investor. Moreover, another supposition behind this rationale IB is that the prices of stock market move proficiently towards the utility maximization nature of an investor (Tong et al., 2020).

But in real world, neither the prices of stock market move like that proficiently as we assumed nor all the investors behave rationally. As traditional theory embraces that sometimes the investors may aimlessly over respond or under respond to the market situations and behave irrationally in constructing their decisions regarding investment (Hilton, 2001). This irrationality is persuaded by different reasons, one of the main reasons of this irrationality is human behavior.

Human behavior may oppose the fundamental prescription, particularly during the market ambiguity and confusion. The human behavior is obsessed by emotional, cognitive, psychological, availability and representative biases which leads to irrationality in their behavior regarding their investment decisions (ID) (Bowers, Greve, Mitsuhashi $\&$ Baum, 2014). Intuition, feelings, and emotions of investors affect their decisions which may result in irrational behavior (Zaidi \& Tauni, 2012). The psyche of investors has strong impact on investment decision making (IDM) (Nguyen \& Nguyen, 2020). Psyche and emotions are the main factors causing biases in IDM. These biases are described as predilections towards errors. Investors are inclined to many illusion, errors and biases while making ID. These biases and errors are also called heuristics (Slugoski, Shields \& Dawson, 1993).

Heuristic refers to relying on things about which one instantly thinks of which makes him/her enable to make quick judgment and decision (Baker \& Nofsinger, 2002). To rely on such things which make people to take good and quick decisions, helps them to avoid laborious checking of facts and analysis, but it also leads to flaws in the likelihood of decision making (Bashir, Azam, Butt, Javed \& Tanveer, 2013). These heuristics cause severe errors in investors decisions which leads them to behave irrationally. The current study focuses on three heuristics commonly used in IDM; availability bias (AB), representative bias (RB) and psychological bias (PB). These biases not only affect laymen, but it is also applied to the experienced investors, which is another reason to select these biases in the current research.

The study also identifies the moderating role of locus of control (LC) in the associations between AB and IDM, RB and IDM and PB and IDM. Naturally, human beings think that an individual's own immersion may change the outcomes but, actually, the memory of humans is not reliable which may create chances of errors (MacLeod \& Daniels, 2000). People also think that an event occurs due to their own efforts causing them to relay on their own perception (Coleman and DeLeire, 2000), which leads them to depend more on heuristics. The current study is therefore conducted to explore the impact of $\mathrm{AB}, \mathrm{RB}$ and $\mathrm{PB}$ on IDM and to test the moderating impact of $\mathrm{LC}$ on the said impact using the primary data collected from investors working in stock markets of Pakistan.

The remainder of the paper is arranged as following: the second section describes the review of literature and construction of hypothesis, section three explains the data and research methodology, section four consists of empirical results, fifth section of the study explains the discussions and conclusions, and at the end, the study provides policy implication, limitations and directions for future-research.

\section{Literature Review}

$\mathrm{RB}$ is defined as correspondence degree of an event with its protective inhabitants (Healy and Palepu, 2001). Investors consider that their prior familiarities and judgements are generally accurate, and on the basis of these previous judgements and familiarities they will make balanced choices in future. That's why investors are stuck in similar pattern of investment again and again that results in a vague image of present situation (Prechter, 2001). Deliberate investors know that it is necessary to make a laborious investigation of current situation before making an ID. However, they had propensity of depending on prior experience, that was disturbing the financial markets (Shimizu, 2007). In capital market, stakeholders do not behave as they should, they behave reasonably without considering their previous judgements (Filbeck, Hatfield \& Horvath, 2005). From the last decade, many studies have been found trying to elaborate some aspects of the representativeness of performance of an investor. Today's stakeholders are significantly attracted by the repute, status and luminary effects of a firm (Pfarrer, Pollock \& Rindovo, 2010). Generally repetitive occurrences are that of observing previous experiences instead of looking onwards, nonetheless investors fail to understand that future results may differ from their previous judgements (Arrfelt et al., 2013). These occurrences are the results of representative behavior of the investors.

\section{$\boldsymbol{H}_{I}: R B$ is positively associated with IDM.}

$\mathrm{AB}$ is a preference in which the managers depend on the existing knowledge, instead of investigating other substitutes and processes that results in irrationality in decision making (Folkes, 1988). It is perceived that investors prefer to invest in such countries, where information can be accessed easily (Waweru, Munyoki \& Uliana, 2008). From the 20th century, researchers found different determinants of $\mathrm{AB}$ that influence IDM. Occasionally, investors make decisions without considering the appropriate information. Moreover, during the period of financial crises, investors suffered more due to their responses based on $\mathrm{AB}$. Rather than estimating 
all the information, investors use only available information that is easily accessible (Wang, Rodan, Fruin \& $\mathrm{Hu}$, 2014). Competition among stakeholders requires investors to respond rapidly to the available information (Bowers et al., 2014) and they depend on shortcuts like AB instead of making rational ID.

\section{$\boldsymbol{H}_{2}: A B$ has positive association with IDM.}

PB is a type of instant reaction of investors at the time of decision making which is defined as an overconfidence of knowing everything (Slugoski et al., 1993). Investors perceive that they know everything and think that they are smarter and have higher information and evidences. Psychological bias effects the ID (Bashir et al., 2013). Investors with psychological bias adversely affect the performance of overall market and make wrong decisions (Wang et al., 2014).

\section{$\boldsymbol{H}_{3}:$ There is a positive relationship between PB and IDM.}

LC is defined as the believes of the person that the anticipated consequences arise due to his own capabilities and aptitudes (Selart, 2005). In IDM, LC expresses about the magnitude or degree to which the LC influences the decision or choice of the investors. If investors consider that they can regulate the situation; they become motivated to make choices of investment. LC is an important interactive factor that is combined in the studies of those factors influencing the purchasing and virtues of consumer decisions making (Ozbek, Alnıaçık, Akkılıç \& Koç, 2013). Decision making of consumers are analogous to the IDM as investment is the purchasing choice of capital resources. Many researchers believe that LC carries the clarification for upcoming outcomes (Hiller \& Hambrick, 2005) and it also clarifies the variations in the behavior of investors (Spector et al., 2002). Moreover, the nature of investment also affects the explanations of an investor about his personal aptitudes and capabilities (Lam \& Schaubroeck, 2000). The LC has its influence on individual investors, and the decision makers who consider that the situation is under their control (Brauer $\&$ Wiersema, 2012). Some investors have no idea about their capabilities (Gervais \& Odean, 2001) and become risk opposed, whereas some investors overvalue their capabilities by thinking that they can alter the market circumstances (Allen \& Evans, 2005). These type of investors believe that they are superior; this belief leads them to irrationality and stupidity in their investment choices. The performance of the investors with internal LC is not well and they make biased decisions (Brauer \& Wiersema, 2012). There is presence of $\mathrm{LC}$ in IDM if an investor expects that the reason and resistor of an investment will be in his/her control (Selart, 2005); therefore, he/she becomes irrational in IDM and his/her decision regarding investment becomes biased.
$\boldsymbol{H}_{4}: L C$ moderates the relationship between (a) $R B$ and IDM, (b) $A B$ and IDM and (c) PB and IDM.

\section{Data and Methodology}

The study is conducted on the factors affecting the investors' decision making (IDM) in Pakistan. The interaction effect of locus of control (LC) is also examined. For this purpose, the primary data are gathered from 300 respondents. The study is conducted among the investors working in the Pakistan's city of Faisalabad. SEM-PLS (assessment of measurement and structural models) is used to analyze the interactions among variables.

For the purpose of the study, a questionnaire is designed comprising of 33 questions. The questionnaire is then divided in to 5 sections. The section 1 focuses on the investors' basic information. The section 2, 3 and 4 comprises $\mathrm{AB}, \mathrm{RB}$ and $\mathrm{PB}$ respectively. In the section 5 , the measure of LC is constructed. The assessment of measures of response on IDM is analyzed in section 6. The study uses two types of questions to be asked from the respondents. The first type of questions consist of multiple-choice questions used to analyze the basic information of the respondents. The second type comprises of Likert type scale and covers the various aspects like AB, RB, PB, LC and IDM. These measurements are based on 5-points Likert scale.

\subsection{Variables Description}

IDM is used as explained while $A B, R B$ and $P B$ are used as explanatory variables. The study also uses LC as moderating variable. The explanation and measurement of these variables are as follows:

\subsubsection{Investors' Decision Making (IDM)}

The determination of assets' full amount to be held in a company refers to as investment decision(ID). It is considered to be the most important decision among financial decisions (Garcia-Sanchez \& Garcia-Meca, 2018). As there is a limited quantity of available funds which also involve costs, the proper utilization of these funds is necessary to achieve the objective of maximization of wealth. As the resources and assets of a company are limited and must require their extreme utilization. Companies should invest these resources and assets to gain highest return (Nguyen, Quang \& Dinh, 2020). ID requires a careful selection of assets in which a company can invest their funds (Filatotchev, Poulsen \& Bell, 2019). A company invests its funds to acquire current as well as fixed assets. The choice of acquiring fixed assets is known as IDM. The measurement of this variable is taken from Scot and Brucee (1995). Out of which the current study only incorporated intuitiveness in the questionnaire as a proxy measure for extent irrational behavior of IDM. The study uses 5 items of decision making to quantify this variable. 


\subsubsection{Availability Bias (AB)}

The tendency of a human to think about those things that readily come to the mind are highly representative than in the case of actual facts, is referred to as AB. The phenomenon of psychology is one for a lot of cognitive biases that hinder the critical thinking which ultimately affects the decisionmaking process (Boone \& Witteloostuijn, 2005). AB is an output which comes from a cognitive short-cut called "availability heuristic". Heuristic refers to rely on the things about which one instantly thinks of which makes him/ her enabled to make quick judgment and decision (Baker $\&$ Nofsinger, 2002). To rely on such things which makes people to take good and quick decisions helps them to avoid laborious checking of facts and analysis, but it is also likely to create flaws in decision making (Bashir et. al., 2013). The measure of $\mathrm{AB}$ comprises of 5 items. Out of which first 2 are taken from a scale of 10 times to measure biases and heuristics by Kudryavatsv, Cohen and Hon-Snir (2013). The 3 rd and 4th items are taken from Lin and Ding (2003). While the item number 5 is taken from Waweru et al. (2008).

\subsubsection{Representative Bias (RB)}

When the similarity of events or objects confuses the thinking of individuals about the uncertainty of an outcome (Arrfelt et. al., 2013), is referred to as RB. The individuals make, frequently, the mistakes of believing those two same events, objects or things are most closely interlinked than they are in-actuality (Bryman \& Bell, 2015). This bias is considered to be the most common error of information processing in the theory of behavioral finance (Bowers et. al., 2014). The measure of RB comprises of 6 items. Out of which first 3 questions identify the investors' extent of representativeness using an item scale of 7 are taken from Lin and Ding (2003). The 4th and 5th items are adopted from Waweru et al. (2008). While the item number 6 is also taken from Lin and Ding (2003).

\subsubsection{Psychology Bias (PB)}

The tendency to take actions or to take decision in an illogical way is referred to as PB. For concern, an individual may feel pressure by the powerful colleagues or may be pressurized to make use of selective data. This measure of $\mathrm{PB}$ consists of 5 items of PB.

\subsubsection{Locus of Control (LC)}

In the psychology of personality, LC refers to the extent to which individuals believe that they have control on the happening of events as opposed to the external factors not in their control. In 1954, this concept was introduced by
Julian Rotter. Individuals having strong internal LC believe that events/objects are derived basically by their own actions (Healy \& Palepu, 2001). For concern, while receiving result of an exam, people having internal LC tend to blame or praise their abilities or themselves. People having believe on external LC tend to blame or praise on external forces. The LC generates much research work in the field of psychology. In order to measure the internal locus of control, an instrument constructed by Furnham (1986) is adapted. This measure consists of 6 items of internal locus of control.

\section{Empirical Results}

\subsection{Demographic Information of Respondents}

The section provides the demographic information of the respondents. $84.67 \%$ respondents are males while other $15.33 \%$ respondents are females. The percentage of married (unmarried) respondents is 59.67 (40.33). 12.33\% of the total respondents are between the age of $18-25$ years, the age of $32 \%$ respondents ranges from $26-33$ years. $29 \%$ of the respondents are 34-41 years old. The percentage of 42-49 years' age respondents is 18.67 while the rest $8 \%$ respondents are above 50. The respondents are also categorized on the basis of investment experience. $28.67 \%$ of the total respondents have $0-5$ years of investment experience, $62.66 \%$ respondents have $6-20$ years' investment experience and $8.67 \%$ of the total respondents have experience of 21 years or above. Out of total respondents, $4.33 \%$ hold the higher secondary school certificate and 29\% hold bachelor's degree. The percentage of respondents with Master's (M. Phil) degree is $51.33(10.34)$ while the rest $5 \%$ have other degrees.

\subsection{Assessment of Measurement Model}

Figure 1 shows measurement model of the study. Crobanch's alpha (CA) is used to determine the scale's reliability. The measurement scales' validity is found to be significant with the values of $0.834,0.791,0.803,0.788$ and $0.960 \mathrm{IDM}, \mathrm{AB}, \mathrm{PB}, \mathrm{RB}$ and $\mathrm{LC}$, respectively. Adequate internal consistency $(\mathrm{CR})$ measured in this research ranged between 0.834 to $0.935(\geq 0.70)$. Furthermore, the study meets the criteria of convergent validity (as measured by AVE) at least 0.50 as suggested by Hair et al. (2011), see Table 1. In line with the previous researchers, to measure multicollinearity with in data, the HTMT ratio must not exceed 0.90 (Toe et al., 2008). The study meets this criterion as the Table 2 shows that the HTMT ratios ranged between 0.241 to 0.504 . The outcomes of discriminate validity are given in Table 3, which suggests that all the off-diagonal value are less than diagonal values (bold values); showing that discriminate validity is present in the data. 


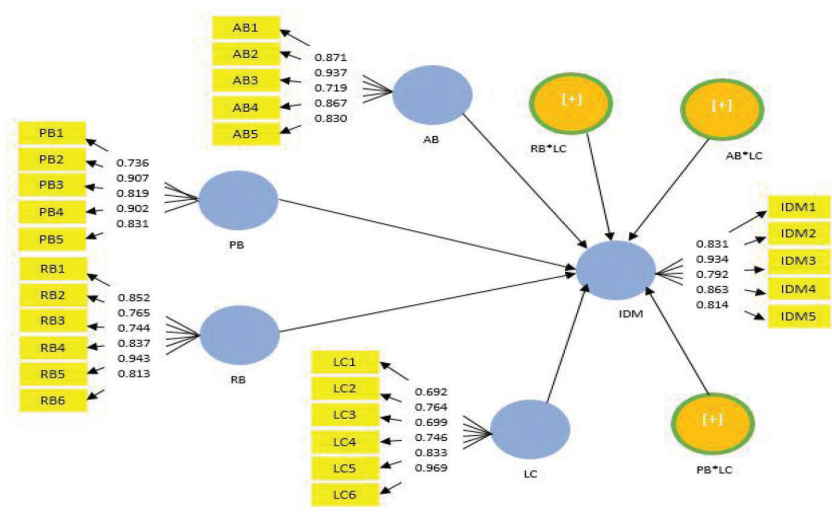

Figure 1: Measurement Model

\subsection{Assessment of Structural Model}

The study measures collinearity issues through VIF which is reciprocal of tolerance. The study is free from collinearity issues as no value is equal to or greater than 0.50 as suggested by Hair et al. (2011), see Table 1. To examine the impact of $\mathrm{RB}, \mathrm{AB}$ and $\mathrm{PB}$ on IDM with the moderation of LC, the study employs PLS-SEM technique (see Figure 2). The results are provided in Table 4. RB has significant positive effect (Coef. 0.147, Prob. 0.020) on irrationality in IDM. An inclination in the level of RB leads to enhance the irrationality of IDM by $14.7 \%$, supporting $\mathrm{H}_{1}$. $\mathrm{AB}$ also has significant positive impact (Coef. 0.374, Prob. 0.000) on IDM. The impact is significant at the level of $1 \%$. It shows that $1 \%$ increase in the level of $\mathrm{AB}$ leads to improve the irrationality in IDM by $37.4 \%$.

Table 1: Measurement Model

\begin{tabular}{|c|c|c|c|c|c|c|}
\hline Construct & Item Code & Loadings & CA & CR & AVE & VIF \\
\hline \multirow{5}{*}{ Investor Decision Making } & IDM1 & 0.831 & \multirow{5}{*}{0.834} & \multirow{5}{*}{0.934} & \multirow{5}{*}{0.763} & \multirow{5}{*}{1.634} \\
\hline & IDM2 & 0.934 & & & & \\
\hline & IDM3 & 0.792 & & & & \\
\hline & IDM4 & 0.863 & & & & \\
\hline & IDM5 & 0.814 & & & & \\
\hline \multirow{5}{*}{ Availability Bias } & AB1 & 0.871 & \multirow{5}{*}{0.791} & \multirow{5}{*}{0.905} & \multirow{5}{*}{0.711} & \multirow{5}{*}{1.451} \\
\hline & AB2 & 0.937 & & & & \\
\hline & AB3 & 0.719 & & & & \\
\hline & $\mathrm{AB} 4$ & 0.867 & & & & \\
\hline & AB5 & 0.830 & & & & \\
\hline \multirow{5}{*}{ Psychology Bias } & PB1 & 0.736 & \multirow{5}{*}{0.803} & \multirow{5}{*}{0.834} & \multirow{5}{*}{0.709} & \multirow{5}{*}{2.671} \\
\hline & PB2 & 0.907 & & & & \\
\hline & PB3 & 0.819 & & & & \\
\hline & PB4 & 0.902 & & & & \\
\hline & PB5 & 0.831 & & & & \\
\hline \multirow{6}{*}{ Representative Bias } & RB1 & 0.852 & \multirow{6}{*}{0.788} & \multirow{6}{*}{0.837} & \multirow{6}{*}{0.718} & \multirow{6}{*}{2.318} \\
\hline & RB2 & 0.765 & & & & \\
\hline & RB3 & 0.744 & & & & \\
\hline & RB4 & 0.837 & & & & \\
\hline & RB5 & 0.943 & & & & \\
\hline & RB6 & 0.813 & & & & \\
\hline \multirow{6}{*}{ Locus of Control } & LC1 & 0.692 & \multirow{6}{*}{0.960} & \multirow{6}{*}{0.910} & \multirow{6}{*}{0.752} & \multirow{6}{*}{2.419} \\
\hline & LC2 & 0.764 & & & & \\
\hline & LC3 & 0.699 & & & & \\
\hline & LC4 & 0.746 & & & & \\
\hline & LC5 & 0.833 & & & & \\
\hline & LC6 & 0.969 & & & & \\
\hline
\end{tabular}

Note: “CA: Cronbach's Alpha, Composite Reliability, AVE: Average Variance Extracted, VIF: Variance Inflation Factor". 
Table 2: Heterotrait-Monotrait Ratio (HTMT)

\begin{tabular}{|l|c|c|c|c|c|}
\hline & IDM & AB & PB & RB & LC \\
\hline IDM & & & & & \\
\hline AB & 0.264 & & & & \\
\hline PB & 0.504 & 0.289 & & & \\
\hline RB & 0.301 & 0.367 & 0.467 & & \\
\hline LC & 0.267 & 0.288 & 0.241 & 0.334 & \\
\hline
\end{tabular}

Table 3: Discriminant Validity (Fornell-Larcker criterion)

\begin{tabular}{|l|c|c|c|c|c|}
\hline & IDM & AB & PB & RB & LC \\
\hline IDM & $\mathbf{0 . 8 3 4}$ & & & & \\
\hline AB & 0.394 & $\mathbf{0 . 7 9 4}$ & & & \\
\hline PB & 0.307 & 0.246 & $\mathbf{0 . 8 2 1}$ & & \\
\hline RB & 0.241 & 0.211 & 0.340 & $\mathbf{0 . 8 8 7}$ & \\
\hline LC & 0.197 & 0.241 & 0.198 & 0.207 & $\mathbf{0 . 7 8 7}$ \\
\hline
\end{tabular}

Table 4: Hypotheses Testing

\begin{tabular}{|l|c|c|c|c|}
\hline Effect & Relation & Coefficient & p-value & Decision \\
\hline Direct & & & & \\
\hline $\mathrm{H}_{1}$ & $\mathrm{RB} \rightarrow$ IDM & 0.147 & $0.020^{\mathrm{b}}$ & $\mathrm{SP}$ \\
\hline $\mathrm{H}_{2}$ & $\mathrm{AB} \rightarrow$ IDM & 0.374 & $0.000^{\mathrm{a}}$ & $\mathrm{SP}$ \\
\hline $\mathrm{H}_{3}$ & $\mathrm{~PB} \rightarrow$ IDM & 0.497 & 0.347 & $\mathrm{NSP}$ \\
\hline $\begin{array}{l}\text { Indirect/ } \\
\text { Moderating }\end{array}$ & & & & \\
\hline $\mathrm{H}_{4 \mathrm{a}}$ & $\mathrm{RB}{ }^{*} \mathrm{LC} \rightarrow \mid \mathrm{DM}$ & 0.167 & 0.301 & $\mathrm{NSP}$ \\
\hline $\mathrm{H}_{4 \mathrm{~b}}$ & $\mathrm{AB}{ }^{*} \mathrm{LC} \rightarrow \mid \mathrm{DM}$ & 0.793 & 0.437 & $\mathrm{NSP}$ \\
\hline $\mathrm{H}_{4 \mathrm{c}}$ & $\mathrm{PB}^{*} \mathrm{LC} \rightarrow \mid \mathrm{DM}$ & 0.591 & 0.228 & $\mathrm{NSP}$ \\
\hline
\end{tabular}

Note: "SP: supported, NSP: not supported, a and b: significant at $1 \%$ and $5 \%$, respectively".

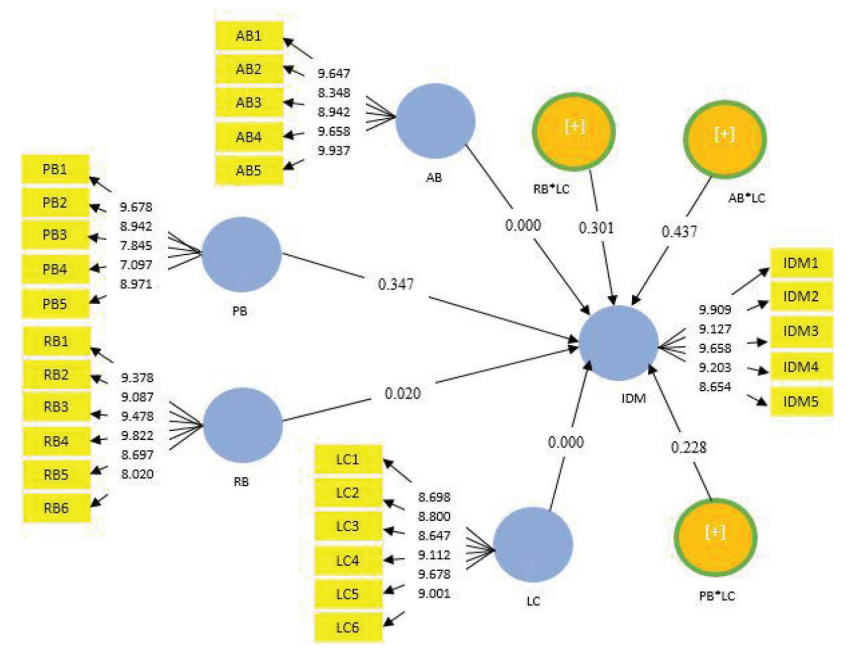

Figure 2: Structural Model
Meaning that more the investors have $\mathrm{AB}$, the higher they are irrational in the process of decision making. Hence, the $\mathrm{H}_{2}$ is supported. Moreover, the study does not find any significant impact of PB on IDM, and hence rejecting $\mathrm{H}_{3}$. Furthermore, the impact of $\mathrm{LC}$ as a moderator on the association between $\mathrm{RB}$ and IDM, $\mathrm{AB}$ and IDM and PB and IDM is found to be insignificant as the probability value is greater than 0.05 , and hence rejecting $\mathrm{H}_{4 a, b \text { and }}$.

\section{Discussions and Conclusions}

Investment behavior is an advanced part of behavioral finance which elaborates that how the decision-making process such as collecting the information, and understanding the situation expected, explored and evaluated by an investor. As traditional theory embraces that sometimes the investors may aimlessly over respond or under respond to the market situations and behave irrationally in constructing their decisions regarding investment. This irrationality is persuaded by different reasons, one of the main reasons is human behavior. The human behavior is obsessed by emotional, cognitive, psychological, availability and representative biases which leads to irrationality in their investment behaviors. Psyche and emotions are the main factors causing biases in IDM. Investors are inclined to many illusion, errors and biases while making investment decisions. These biases and errors are called heuristics; causing severe errors in investors decisions which leads them to behave irrationally. The current study focuses on three heuristics commonly used in IDM; $\mathrm{AB}, \mathrm{RB}$ and $\mathrm{PB}$ and analyzes the moderating role of $\mathrm{LC}$ in the association between IDM and three biases; AB, RB and PB.

The findings show that $A B$ has significant positive impact on IDM. $1 \%$ increase in the level of $\mathrm{AB}$ leads to improve the irrationality in IDM by $37.4 \%$ which means that more the investors have $\mathrm{AB}$, the highly irrational they are in the process of decision making. RB also has significantly positive effect on irrationality of decision making by the investors. An inclination in the level of RB leads to enhance the irrationality of investor's decision making by $14.7 \%$. Conclusively, there is significant positive impact of $\mathrm{RB}$ and $\mathrm{AB}$ on IDM, hence, accepting $\mathrm{H}_{1}$ and $\mathrm{H}_{2}$. The outcomes are similar with prior studies (Bashir et al., 2013; Waweru et al., 2008). The findings confirm that Pakistani investors are influenced by the various behavioral factors. The study of such factors provides greatest insight to understand the behavior of Pakistani investor. The results imply that decisions made by Pakistani investors are driven by the most easily or currently available information and they trust on the information obtained from family and friends without any authentication and verification. The study could not find any moderating role of LC. One possible description of insignificant moderation effect of LC can be the sample 
traits used in the study, e.g., personal characteristics, that change from culture to culture. Another description of these findings may be the association between heuristic biases, including $\mathrm{RB}, \mathrm{AB}$, and $\mathrm{PB}$ and decision-making regarding investment is not personality specific. Investors may rely on the shortcuts of mental gained through experience and knowledge.

\subsection{Practical Implications}

The current study affirms and explains the causes for the stock market deviation from standard rational behavior as described by the existing financial models, which claims that behavioral biases (such as AB, RB, PB) influence the investors which lead investors to deviate from rational behavior. The current study helps in explaining the different phenomenon that traditional study fails to describe, such as herding behavior, focusing on a specific and popular stock, underpricing and overpricing etc. Hence, providing a deep understanding of real-life behavior of investors. The study helps investors as well as investment managers to best understand their own behavior by "keeping in mind the factors affecting their decision deviate from decisions of wealth maximization." The study helps investors to analyze and consider information available to them, more effectively before taking investment decision. In order to avoid the biases' effect and to improve decision making, awareness and training on behavior factors should be provided. The findings also help investment firms seeking to understand and analyze the trends of market in a highly rigorous way and give consultancy of reliable information on the basis of real-life behavior of investors. The study also helps policy makers in understanding the investors and devising policies that keep in view the above said psychological factors to ensure the market's smooth running. The results also imply that decisions made by Pakistani investors are driven by the most easily or currently available information and they trust on the information obtained from family and friends without any authentication and verification.

\subsection{Recommendations}

The investors use stereotyped or similar information while making investment decision regarding investment and prefer to purchase local stock. Pakistani investors, because of the impact of these biases, "wrongly believe that stocks of well reputed firms lead to higher returns. These heuristics lead investors to fail to diversify their portfolio. The current study, therefore, recommends investors to evaluate the degree of bias they themselves have, and then to make financial decisions by keeping that in mind." After examining information from stock market, they should dually verify the figures and facts.

\subsection{Limitations and Future Directions}

The study is limited to analyze the effect of just three biases; AB, RB and PB. The future researchers may enhance the current study's scope by considering other relevant biases in the model. The existence of females in the study sample is very low, the future studies should incorporate adequate representation of females in order to get more accurate results.

\section{References}

Allen, W. D., \& Evans, D. A. (2005). Bidding and overconfidence in experimental financial markets. The Journal of Behavioral Finance, 6(3), 108-120. https://doi.org/10.1207/ s15427579jpfm0603_1

Arrfelt, M., Wiseman, R. M., \& Hult, G. T. M. (2013). Looking backward instead of forward: Aspiration-driven influences on the efficiency of the capital allocation process. Academy of Management Journal, 56(4), 1081-1103. https://doi. org/10.5465/amj.2010.0879

Baker, H. K., \& Nofsinger, J. R. (2002). Psychological biases of investors. Financial Services Review, 11(2), 97-116. https://search.proquest.com/openview/a06bf8da7ca/1?pqorigsite $=$ gscholar \&cbl $=31458$

Bashir, T., Azam, N., Butt, A. A., Javed, A., \& Tanvir, A. (2013). Are Behavioral Biases Influenced By Demographic Characteristics \& Personality Traits? Evidence from Pakistan. European Scientific Journal, 9(29), 277-293. http://eujournal.org/index. $\mathrm{php} / \mathrm{esj}$

Boone, C., \& Van Witteloostuijn, A. (2005). Team locus-of-control composition, leadership structure, information acquisition, and financial performance: A business simulation study. Academy of Management Journal, 48(5), 889-909. https://doi.org/10.5465/ amj.2005.18803929

Bowers, A. H., Greve, H. R., Mitsuhashi, H., \& Baum, J. A. (2014). Competitive parity, status disparity, and mutual forbearance: Securities analysts' competition for investor attention. Academy of Management Journal, 57(1), 38-62. https://doi.org/10.5465/ amj.2011.0818

Brauer, M. F., \& Wiersema, M. F. (2012). Industry divestiture waves: How a firm's position influences investor returns. Academy of Management Journal, 55(6), 1472-1492. https:// doi.org/10.5465/amj.2010.1099

Bryman, A., \& Bell, E. (2015). Business research methods. New York, NY: Oxford University Press.

Coleman, M., \& DeLeire, T. C. (2000). An Econometric Model of Locus of Control and the Human Capital Investment Decision. The Journal of Human Resources, 38(3), 701-721. https://doi. org/10.3368/jhr.XXXVIII.3.701

Filatotchev, I., Poulsen, A., \& Bell, R. G. (2019). Corporate governance of a multinational enterprise: Firm, industry and institutional perspectives. Journal of Corporate Finance, 57(8), 1-8. https://doi.org/10.1016/j.jcorpfin.2018.02.004 
Filbeck, G., Hatfield, P., \& Horvath, P. (2005). Risk aversion and personality type. The Journal of Behavioral Finance, 6(4), 170-180. https://doi.org/10.1207/s15427579jpfm0604_1

Folkes, V. S. (1988). Recent attribution research in consumer behavior: A review and new directions. Journal of Consumer Research, 14(4), 548-565. https://doi.org/10.1086/209135

Furnham, A. (1986). Economic locus of control. Human Relations, 39(1), 29-43. https://doi.org/10.1177\%2F001872678603900102

García-Sánchez, I. M., \& García-Meca, E. (2018). Do talented managers invest more efficiently? The moderating role of corporate governance mechanisms. Corporate Governance: An International Review, 26(4), 238-254. https://doi.org/10.1111/ corg. 12233

Gervais, S., \& Odean, T. (2001). Learning to be overconfident. Review of Financial Studies, 14(1), 1-27. https://doi. org/10.1093/rfs/14.1.1

Hair, J. F., Ringle, C. M., \& Sarstedt, M. (2011). PLS-SEM: Indeed a silver bullet. Journal of Marketing Theory and Practice, 19(2), 139-152. https://doi.org/10.2753/mtp1069-6679190202

Healy, P. M., \& Palepu, K. G. (2001). Information asymmetry, corporate disclosure, and the capital markets: A review of the empirical disclosure literature. Journal of Accounting and Economics, 31(1), 405-440. https://doi.org/10.1016/S01654101(01)00018-0

Hiller, N. J., \& Hambrick, D. C. (2005). Conceptualizing executive hubris: The role of (hyper-) core self-evaluations in strategic decision-making. Strategic Management Journal, 26(4), 297-319. https://doi.org/10.1002/smj.455

Hilton, D. J. (2001). The psychology of financial decision-making: Applications to trading, dealing, and investment analysis. The Journal of Psychology and Financial Markets, 2(1), 37-53. https://doi.org/10.1207/S15327760JPFM0201_4

Kudryavtsev, A., Cohen, G., \& Hon-Snir, S. (2013). "Rational"or'Intuitive': Are Behavioral Biases Correlated Across Stock Market Investors? Contemporary Economics, 7(2), 31-53. https://ssrn.com/abstract=2286065

Lam, S. S., \& Schaubroeck, J. (2000). The role of locus of control in reactions to being promoted and to being passed over: A quasi experiment. Academy of Management Journal, 43(1), 66-78. https://doi.org/10.5465/1556386

Lin, C. P., \& Ding, C. G. (2003). Modeling information ethics: The joint moderating role of locus of control and job insecurity. Journal of Business Ethics, 48(4), 335-346. https://doi. org/10.1023/B:BUSI.0000005745.63324.79

MacLeod, C. M., \& Daniels, K. A. (2000). Direct versus indirect tests of memory: Directed forgetting meets the generation effect. Psychonomic Bulletin \& Review, 7(2), 354-359. https:// doi.org/10.3758/BF03212993

Nguyen, D. D., \& Nguyen, C. V. (2020). The Impact of Operating Cash Flow in Decision-Making of Individual Investors in Vietnam's Stock Market. Journal of Asian Finance, Economics, and Business, 7(5), 19-29. https://doi.org/10.13106/jafeb.2020. vol7.no5.019
Nguyen, T. V. N., Quang, T., \& Dinh, C. H. (2020). Factors Affecting Employees' Organizational Commitment in Foreign Direct Investment Enterprises. Journal of Asian Finance, Economics and Business, 7(10), 413-421. https://doi.org//jafeb.2020.vol7. no10.413

Ozbek, V., Alnıaçık, Ü., Akkılıç, M. E., \& Koç, F. (2013). The Moderating Role of Locus of Control on the Links between Perceived Ethical Problem and Ethical Intentions of Marketing Managers in Turkey. Procedia-Social and Behavioral Sciences, 99(11), 265-273. https://doi.org/10.1016/j.sbspro.2013.10.494

Pfarrer, M. D., Pollock, T. G., \& Rindova, V. P. (2010). A tale of two assets: The effects of firm reputation and celebrity on earnings surprises and investors' reactions. Academy of Management Journal, 53(5), 1131-1152. https://doi.org/10.5465/ amj.2010.54533222

Prechter Jr, R. R. (2001). Unconscious herding behavior as the psychological basis of financial market trends and patterns. The Journal of Psychology and Financial Markets, 2(3), 120-125. https://doi.org/10.1207/S15327760JPFM0203_1

Scott, S. G., \& Bruce, R. A. (1995). Decision-making style: The development and assessment of a new measure. Educational and Psychological Measurement, 55(5), 818-831. https://doi. org/10.1177\%2F0013164495055005017

Selart, M. (2005). Understanding the role of locus of control in consultative decision-making: A case study. Management Decision, 43(3), 397-412. https://doi. org/10.1108/00251740510589779

Shimizu, K. (2007). Prospect theory, behavioral theory, and the threat-rigidity thesis: Combinative effects on organizational decisions to divest formerly acquired units. Academy of Management Journal, 50(6), 1495-1514. https://doi. org/10.5465/amj.2007.28226158

Slugoski, B. R., Shields, H. A., \& Dawson, K. A. (1993). Relation of conditional reasoning to heuristic processing. Personality and Social Psychology Bulletin, 19(2), 158-166. https://doi. org/10.1177\%2F0146167293192004

Spector, P. E., Cooper, C. L., Sanchez, J. I., O’Driscoll, M., Sparks, K., Bernin, P. others. (2002). Locus of control and well-being at work: How generalizable are western findings? Academy of Management Journal, 45(2), 453-466. https://doi. org/10.5465/3069359

Teo, T. S., Srivastava, S. C., \& Jiang, L. (2008). Trust and electronic government success: An empirical study. Journal of Management Information Systems, 25(3), 99-132. https://doi. org/10.2753/mis0742-1222250303

Tong, K. H., Nguyen, Q. L. H. T. T., Nguyen, T. T. M., Nguyen, P. T., \& Vu, N. B. (2020). Applying the Fuzzy DecisionMaking Method for Program Evaluation and Management Policy of Vietnamese Higher Education. Journal of Asian Finance, Economics, and Business, 7(9), 719-726. https://doi. org/10.13106/jafeb.2020.vol7.no9.719

Wang, C., Rodan, S., Fruin, M., \& Xu, X. (2014). Knowledge networks, collaboration networks, and exploratory innovation. 
Academy of Management Journal, 57(2), 484-514. https://doi. org/10.5465/amj.2011.0917

Waweru, N. M., Munyoki, E., \& Uliana, E. (2008). The effects of behavioural factors in investment decision-making: a survey of institutional investors operating at the Nairobi Stock Exchange. International Journal of Business and
Emerging Markets, 1(1), 24-41. https://doi.org/10.1504/ IJBEM.2008.019243

Zaidi, F. B., \& Tauni, M. Z. (2012). Influence of Investor's Personality Traits and Demographics on Overconfidence Bias. Institute of Interdisciplinary Business Research, 4(6), 730-746. https://journal-archieves24.webs.com/730-746.pdf 